\title{
Factors Influencing Modern Contraceptive Use among Adolescents in Nepal
}

\author{
Ranjeeta Subedi, ${ }^{1}$ Israt Jahan, ${ }^{2}$ Pam Baatsen ${ }^{3}$ \\ ${ }^{1}$ Nepal Health Research Council, Ramshahpath, Kathmandu, Nepal. ${ }^{2}$ CSF Global, Dhaka, Bangladesh, \\ ${ }^{3}$ Royal Tropical Institute, Amsterdam, Netherlands.
}

\section{ABSTRACT}

In Nepal, contraceptive use among married adolescents is low and has remained nearly stagnant since 2006, while little information is available about contraceptive use among unmarried adolescents. Nepal is committed to improve sexual and reproductive health rights among all the adolescents. Promoting modern contraceptive use especially among married adolescents is one of the key approaches in practice, to prevent HIV or sexual transmitted infections, avoid unintended pregnancy and sub-sequent unsafe abortion. In spite of these efforts, modern contraceptive use among married adolescents is not increasing. In this study, we aimed to review the prevalence and trends as well as factors influencing modern contraceptive use among both married and unmarried adolescents in Nepal.

A review of existing published and unpublished articles, documents, and reports were conducted. An adapted and modified socio-ecological model was used to explore the factors influencing contraceptive use.

Contraceptive use is persistently low among adolescents. Various interrelated factors like socio-cultural norms and traditions, lack of comprehensive knowledge on contraceptive methods among adolescents, inadequate adolescent friendly Services and health workers not having the competencies to work with adolescents, are the major influential factors that limit adolescents to seek and use contraceptive services and information.

A multilevel approach is required to address the interrelated factors and to create an enabling environment in which adolescent are fully informed and equipped to make use of contraceptives and related services. For this to happen, Government and NGOs working on sexual and reproductive health rights have to work towards translating the existing policies into practice. Involving adolescents, their families and communities; equipping teachers to provide comprehensive sex education within school and sex education programme for out of school and enhancing the competencies of health workers to provide adolescent friendly services - all in line with the written policy - is urgently needed.

Keywords: Adolescent; barriers; contraceptive; Nepal; SRHR.

\section{INTRODUCTION}

Access to contraceptives is a basic reproductive right, and essential to avoid unintended pregnancies which have become a rising public health issue in $\operatorname{Nepal}(50 \%$ of pregnancies were reported unintended among women of reproductive age, 2014). ${ }^{1}$ Adolescents make up nearly a quarter $(24.2 \%)$ of the population in Nepal. ${ }^{2}$ Due to a combination of biological, social and psychological factors, adolescents are more vulnerable to a range of health problems such as Sexually Transmitted Infections (STIs), HIV, early and repeat pregnancies. ${ }^{3}$ Nonetheless adolescents are very energetic and receptive to information applicable to them. ${ }^{3}$ However, sexual and reproductive health education and services are disproportionately low in comparison to the needs of adolescents. ${ }^{3,4}$ Although government and NonGovernment organizations are working to provide information and services, adolescent contraceptive use is minimal. To address this, there is a need to understand the current scenario and trends of contraceptive use and factors affecting the demand, access and use of contraceptives among adolescents which the review aims at.

\section{METHODS}

The study is based on review of all available literature, including published studies in peer reviewed journals as well as unpublished studies and reports, related to factors influencing contraceptive use among adolescents
DOI: http://dx.doi.org/10.3126/

inhrc.v16i3.21419
Correspondence: Ranjeeta Subedi, Nepal Health Research Council (NHRC), Ramshahpath, Kathmandu, Nepal. Email: knockranju2012@gmail.com, Phone+9779803148019. 
in Nepal. Google, Google Scholar, Yahoo search, PubMed, Medline, EMBASE, Scopus and the VU e- library are the major search engines and or databases used for the review. Google was used to find various sources like WHO, UNICEF, Guttmacher Institute, Nepal Ministry of Health and Population (MoHP), Nepal Demographic Health Surveys (NDHS), Department of Health Service (DoHS) and Central Bureau of Statistics. From these websites, factual information was collected in addition to policy documents and guidelines. Google Scholar and PubMed were used to find relevant abstracts of peer reviewed articles in different journals. These abstracts were further screened and if relevant, full articles were retrieved. Where problems arose with finding full articles, an additional search was done using the VU e-library and Yahoo search. Bibliographies of peer reviewed articles were also used to search for additional relevant articles. The NDHS from 1996-2016were the major sources for reviewing the pattern and trend of contraceptive use among adolescents.

\section{RESULTS AND DISCUSSION}

\section{Prevalence and trends of contraceptive use}

With considerable effort and nationwide campaigns, use of modern contraceptives among the population as a whole has almost doubled in last 20 years in Nepal, though, the overall contraceptive prevalence rate (CPR) among currently married women is still low (43\% in 2016). ${ }^{5}$ When it comes to currently married female adolescents(aged $15-19$ years), the modern CPR is substantially lower $(14.5 \%$ in 2016)and limited to few methods such as injectable contraceptives- (5.5\% in 2016), male condoms $(4.4 \%$ in $2016)$, pill (2.2\% in 2016), implants (2.1\% in 2016) and IUD (0.2\% in 2016). ${ }^{5}$ Although, the modern CPR among married female adolescents in Nepal has increased by more than three-fold in the last 20 years $(4.4 \%$ in 1996, $14.5 \%$ in 2016), the top preferences have been limited to condoms and injectable contraceptives. ${ }^{5-10}$ Although the national demographic and health survey (DHS) only presents data for contraceptive use among married female adolescents, in one comparative study of the DHS around the world reported that unmarried adolescents use more modern method of contraceptive and also have more unmet needs of contraceptives than the currently married ones. ${ }^{11}$

Furthermore, since 2009 steep increase in the use of emergency contraceptive Pills (ECPs) among unmarried girls and married women below 25 has become a growing concern in Nepal. ${ }^{12,13}$ Moreover, following the legalization of abortion and initiation of Comprehensive Abortion Services (CAC) in 2004, 'abortion' has been increasing in $\mathrm{Nepal}^{14}$ the scenario is no different among young people in Nepal. ${ }^{12}$ Therefore, the concern remains if ECs and abortions are been used as alternatives to modern contraceptives in Nepal among many adolescents as quoted by some of the experts working in SRH, doctors, medical shopkeepers in the newspaper. ${ }^{13}$ However, there is lack of evidence to support this statement.

Factors influencing modern contraceptive use among adolescents

The literature review shows that the low use of contraceptive use by married and unmarried female adolescents is influenced by many interrelated multilayered factors. Most of these factors are associated with socio-cultural, knowledge and service delivery related barriers.

\section{Socio economic factors}

Modern contraceptive use among adolescents has been found to be influenced by several socio-economic factors such as their formal educational level, economic status, religion and marital status.

In Nepal, education in general is found to have a positive impact on contraceptive use among adolescents as shown by the fact that condom use by the young men between 15-24 years with education 10 class or above is ten times higher than young men without formal education (53.7\% vs. 5.3\%). ${ }^{15}$ Similarly, NDHS 2011 also showed that young people (15-24years) without formal education were found six times more likely to have sexual intercourse by age of 18 than those with formal education. ${ }^{6}$ The wealth of the family has not shown to have an influential impact on the use of contraceptive. ${ }^{5,6}$ Even though, in order to avoid constrain of wealth in affording contraceptive, government of Nepal has made the contraceptive methods available free of cost.

Furthermore, evidence indicates that individual religion or beliefs and marital status influence their sexual behaviour. ${ }^{16,17}$ The scenario is no different in Nepal.Adolescent boys who follow Hindu religion were reported nearly three times (odds ratio=2.5) more likely to involve in premarital sex than who believe in other religions. ${ }^{18}$ Moreover, in Nepal, $23.1 \%$ female adolescents aged $15-19 y$ rs get married. ${ }^{19}$ With the norm of proving fertility soon after marriage due to societal and familial pressure, it is not surprising that the CPR is low among married female adolescents. ${ }^{5}$ Although, as result of rapid urbanization and improved education, early marriages are now in a declining trend. However, delay in marriage might have caused an increasing trend of male adolescents getting involved in premarital sexual activities in Nepal. ${ }^{4}$ Although the policy does not discriminate between married and unmarried adolescents 
in relation to contraceptive service provision, the strong restrictive cultural norm of premarital sex, ${ }^{18}$ prevents adolescents from seeking modern contraceptives in fear of exposure, shame and embarrassment. ${ }^{20}$

\section{Cultural and traditional norms}

Evidence indicates that deeply rooted socio-cultural norms and beliefs cross-cut different interlinked factors and influence contraceptive use among adolescents. With the restrictive cultural norms around sexuality and fear of promoting premarital sex, family members and other adults i.e. teachers rarely discuss issues like puberty, changes in the body, sex, and contraceptives with adolescents specially those who are unmarried. ${ }^{21-23}$ These issues are often considered as matter of privacy. Although, discussing sexual reproductive health issues with family members specially parents early on during adolescents has been found effective in delaying sexual debut and promoting safer sex practice using contraceptives. ${ }^{22,24}$ However, the culturally rooted stigma and embarrassment around it make adolescents unwilling to discuss SRH issues with their family members, friends of opposite sex and even sexual partners. ${ }^{25}$ Furthermore, the stigma and fear of getting recognized and spreading the information regarding sexual behaviour to the family members and relatives prevents adolescents specially those living in rural areas from seeking consultation and support regarding SRH and modern contraceptive use (i.e. condoms) from local shopkeepers and health care providers. ${ }^{25}$ In one study, it was also reported that young people turn to peers for consultation regarding $\mathrm{SRH}$ first. ${ }^{25}$ Evidence also suggest significant role of peers in adolescent's knowledge, attitude and specially practice regarding SRH and contraceptives. . $^{18,26,27}$

Even in marriage, culturally men are founddominant in making decisions regarding contraceptive use in Nepal, ${ }^{28}$ which might be consistent for adolescents as well. Although, in different studies, women's autonomy and spousal communication about FP has been found beneficial in increasing contraceptives use despite other inhibiting factors. ${ }^{29,30}$ However, the cultural norms are hindering adequate use of modern contraceptive among married and unmarried adolescent in Nepal. To overcome such barriers, there is a persistent need to address the indigenous traditional norms. Community sensitization, use of information, education, and communication (IEC) materials and behaviour change communication (BCC) at the local level could have an effective role in addressing these issues to some extent. ${ }^{31,32}$

Knowledge and perceptions

Improving knowledge level regarding modern contraceptive methods and related services along with increasing self-efficacy or empowerment has been recommended as an opportunity to assist adolescents in making better decision regarding FP and contraceptive use. ${ }^{3}$ However, in Nepal, adolescents irrespective of their marital status, do not possess comprehensive knowledge regarding efficacy, side effects, source, use and available SRH services ${ }^{33-35}$ Moreover, knowledge by itself is not sufficient to translate this into practice. ${ }^{36,37}$ Misconceptions regarding use and side effects of different modern contraceptive has resulted in poor practice of modern contraceptives among adolescents in Nepal, and this finding is consistent for both married and unmarried ones. ${ }^{31,33}$ Adolescents receive most of the information regarding $\mathrm{SRH}$ and contraceptive use from media targeted at the general population, ${ }^{25,38}$ also from peers and other informal sources..$^{39,40}$ Educational institution could play a good role here in providing basic SRH information. However, in reality, inadequate education and teaching approaches in educational institutions is one of the major obstacles for ensuring adolescents obtain comprehensive SRHR information from formal sources. ${ }^{22,41}$ Although, the comprehensive sexuality education (CSE) has already been integrated in the curriculum of lower secondary and secondary level in Nepal, a recent study showed notable gaps in delivering the key messages due to insufficient trained teachers for CSE implementation. ${ }^{42}$ The negligence, inadequate training, along with cultural belief shaped by traditional norms makes the educators reluctant and judgmental to provide information. ${ }^{23}$ Disregarding the knowledge level, adolescent's individual perception also influences their practice of contraceptive use and having sex. Studies have revealed that use of modern contraceptive is often considered as indication of having sexually transmitted disease or being unfaithful to the partner among adolescents..$^{43,44}$ Moreover, the perceived benefit of alcohol and drug abuse in reducing fear of rejection or diseases or enhancing sexual pleasure also found to influence adolescents attitude and practice toward modern contraceptive use in Nepal. 4,23,45,46

All these signify the need of providing comprehensive sexuality education with special focus on adolescents. To overcome these barriers and equip adolescents with the necessary knowledge and skills to better protect themselves, multi-level interventions are required. Coordination between Ministry of Health and Ministry of Education to revise the existing curriculum and introducing sex education and other school-based SRH program earlier than the secondary level could play an effective role here. Involving peer educators to raise awareness and change attitudes towards appropriate contraceptive use among adolescents has been previously found beneficial in different interventions in Nepal. ${ }^{31}$ 
Service delivery

Availability and accessibility of modern contraceptives influence the utilization of SRH services by the adolescents. Although, government facilities supply $70 \%$ of the contraceptives used in the country. ${ }^{5}$ However, these health facilities were also not reported adolescent friendly(i.e. confidentiality, service provider's behaviour) in studies conducted among adolescents in Nepal. ${ }^{25}$ Even though, the contraceptives are provided free of cost in public facilities, only $51 \%$ of currently married adolescent (15-19yrs) female seek contraceptives from governmental sources. ${ }^{15}$ Although the national Adolescent Sexual Reproductive Health (ASRH) program initiated by the Adolescent Friendly Services (AFS), has made an effort to make the services more available for adolescents in 63 districts of Nepal, however, this is not entirely successful. This is because many of the adolescents are not aware that such services exist, in addition, there are issues also with the quality of the services due to staffing issues as well as guidelines not being followed. ${ }^{35,47}$ Moreover, the judgemental attitude and reluctance of health service providers make it more difficult for adolescents to seek these services. ${ }^{4,40}$ The perceived embarrassment of asking services from opposite gender as well as the discomfort of health care providers in discussing SRH issues among adolescents especially unmarried ones have also been identified as the barriers in accessing and utilizing these services. . $^{4,25,35,40}$

In addition, the service hours, distance, and location of the service centreswere the perceived challenges in getting services by the adolescents. ${ }^{35}$

Multi-level initiatives have been taken to improve this situation. Major initiatives mostly focus on enhancing counselling, awareness raising, advocacy, increasing availability of youth friendly SRH services including FP, contraceptive marketing, safe abortion, and capacity building through training. , $4,38,41,49-52$ However, they are in very initial stage. Furthermore, these programmes are available mostly in urban areas, ${ }^{25}$ which only covers less than one fourth $(16.1 \%)$ of the adolescents. ${ }^{19}$

\section{CONCLUSIONS}

Although the adolescent health strategy addressing the contraceptive needs, and guidelines developed by $\mathrm{MoH}$ are in place, it is not well implemented. Moreover, the arrangement of the facilities, lack of assurance of adolescent's privacy and confidentiality makes them avoiding seeking contraceptives. Evidence from other LMICs indicates, multi-level approach is required to promote contraceptive use and bring positive concept of sexuality among adolescents. Interventions to mobilize peer educators, health workers, parents of the adolescents and local community members; empower women in negotiation and decision-making skills, male involvement in different FP projects have been found effective previously. All these evidences should be kept under consideration while planning intervention focusing modern contraceptive use among adolescents in Nepal.

\section{ACKNOWLEDGEMENTS}

My sincere thankfulness goes to the people and Government of the Netherlands for the Nuffic scholarship that have provided me opportunity to develop my career.

I would like to thank Royal Tropical Institute, Course Director, Course Coordinators, Facilitators and all the staffs of KIT for their ongoing support, inspiration and guidance.

I am very grateful to my thesis backstopper Ankie Broek, who continuously provided me guidance, encouragement and valuable support throughout the thesis. I truly appreciate your tremendous instructions that have made my thesis successful and helped me to learn many things.

\section{REFERENCES}

1. Puri, M., Singh, S., Sundaram, A., Hussain, R., Tamang, A., \& Crowell, M. Abortion Incidence and Unintended Pregnancy in Nepal. Int Perspect Sex Reprod Health. 2016. 42(4), 197-209.[Full Text]

2. Government of Nepal, National Planning Commission Secretariate, Central Bureau of Statistics. Population Monograph of Nepal Vol I Population Dynamics. Ramshahpath, Kathmandu, Nepal:Central Bureau of Statistics; 2014.ISBN 978-9937-2-8971-9. [Full Text]

3. Family Health Division, Department of Health Service, Ministry of Health. National Adolescent Health and Development Startegy. Nepal. Ministry of Health; 2000. 1p.[Full Text]

4. Regmi P, Simkhada P, Van Teijlingen ER. Sexual and reproductive health status among young people in $\mathrm{Ne}$ pal: opportunities and barriers for sexual health education and services utilization. Kathmandu Univ Med J. 2008;6(22):248-56.[Full Text]

5. Ministry of Health, Nepal; New ERA; and ICF. 2017. Nepal Demographic and Health Survey 2016: Key Indicators. Kathmandu, Nepal: Ministry of Health, Nepal.[Full Text]

6. Ministry of Health and Population (MOHP) [Nepal], New ERA, and ICF International Inc. Nepal Demographic and Health Survey 2011. Kathmandu, Nepal: Ministry of Health and Population, New ERA, and ICF International, Calverton, Maryland;2012. [Full Text] 
Factors Influencing Modern Contraceptive Use among Adolescents

7. Central Bureau of Statistics, 2015. Nepal Multiple Indicator Cluster Survey 2014, Final Report.Kathmandu, Nepal: Central Bureau of Statistics and UNICEF Nepal.[Full Text]

8. Pradhan A, Aryal RH, Regmi G, Ban B, Govindasamy P. 1997. Nepal Family Health Survey 1996. Kathmandu, Nepal and Calverton, Maryland: Ministry of Health [Nepal], New ERA, and Macro International Inc.[Full Text]

9. Ministry of Health [Nepal], New ERA, ORC Macro. 2002. Nepal Demographic and Health Survey 2001. Calverton, Maryland, USA: Family Health Division, Ministry of Health; New ERA; and ORC Macro.[Full Text]

10. Ministry of Health and Population (MOHP) [Nepal], New ERA, and Macro International Inc. 2007. Nepal Demographic and Health Survey 2006. Kathmandu, Nepal: Ministry of Health and Population, New ERA, and Macro International Inc.[Full Text]

11. Khan, Shane, Mishra V. Youth Reproductive and Sexual Health. DHS Comparative Reports No. 19. Calverton, Maryland, USA: Macro International Inc. 2008 August. 87p. [Full Text]

12. Thapa S. A new wave in the quiet revolution in contraceptive use in Nepal : the rise of emergency contraception. Reproductive Health; 2016;13:49.[Full Text]

13. Usha KC. Nepalese Teen Girls Endanger Their Health Through Overuse of Morning-After Pill [Internet]. Global Press Journal (Weekend edition). 2014 June 4. [Link]

14. Shrestha DR, Shrestha A, Ghimire J. Emerging Challenges in Family Planning Programme in Nepal. J Nepal Health Res Council. 2012;10(21):108-12.[PubMed]

15. Khatiwada N., Silwal P.R., Bhadra R., Tamang T.M. Sexual and Reproductive Health of Adolescents and Youth In Nepal: Trends and Determinants: Further analysis of the 2011 Nepal Demographic and Health Survey. Calverton, Maryland, USA: Nepal Ministry of Health and Population, New ERA, and ICF International.2013 March. p.1-33. [Full Text]

16. Srikanthan A, Reid RL. Religious and Cultural Influences on Contraception. J Obstet Gynaecol Can. 2008;30(2):129-37. [PubMed]

17. Shah NA, Nisar N, Qadri MH. Awareness and pattern of utilizing family planning services among women attending Urban Health Care Center Azizabad Sukkur. Pak J Med Sci 2008;24(4): 550-5.[Full Text]

18. Adhikari R, Tamang J. Premarital Sexual Behavior among male college students of Kathmandu, Nepal. BMC Public health. 2009.15;9:1-9. [Full Text]

19. Government of Nepal, National Planning Commission Secretariate, Central Bureau of Statistics. Population
Monograph of Nepal Vol II Social Demography. Ramshahpath, Kathmandu, Nepal:Central Bureau of Statistics; 2014.ISBN 978-9937-2-8972-6[Full Text]

20. Sexton M, Petroni S, Kanesathasan A, Edmeades J, Warner A, Stoebenau K, et al. Understanding the Adolescent Family Planning Evidence Base. International Centre for Research on Women (ICRW). 2014, July:1-68.[Link]

21. Acharya DR, Van Teijlingen ER, Simkhada P. Opportunities and challenges in school-based sex and sexual health education in Nepal. Kathmandu Univ Med J. 2009; 7(28):44553.[Link]

22. Simkhada PP, Acharya DR, Schildbach E, Silwal PR, Teijlingen ER, Shresthe J, Pandey PL. Sexual and Reproductive Health of Adolescents in Rural Nepal: Knowledge, Attitudes and Behaviour. Nepal Population Journal 2012; 17(16):1-835. [Full Text]

23. Pokharel S, Kulczycki A, Shakya S. School-Based Sex Education in Western Nepal: Uncomfortable for Both Teachers and Students. Reprod Health Matters. 2006;14(28):15661.[Full Text]

24. Palatnik A, Seidman DS. Survey of opinions of mothers and teenage daughters on sexual behavior and contraception : descriptive study and literature review. Int J Women’s Health. 2012;4:265-70.[Full Text]

25. Regmi PR, Teijlingen EVan, Simkhada P, Acharya DR. Barriers to Sexual Health Services for Young People in Nepal. J Health Popul Nutr. 2010;28(6):619-27.[Full Text]

26. Puri M. Sexual Risk Behaviour and Risk Perception of Unwanted Pregnancy and Sexually Transmitted Infection among Young Factory Workers in Nepal.Centre for Research on Environment Health and Population Activities (CREPHA). 2002 April;1-68. [Link]

27. Ali MM, Amialchuk A, Dwyer DS. Social Network Effects in Contraceptive Behavior among Adolescents. J Dev Behav Pediatr. 2011; 32(8): 563-71. doi: 10.1097/ DBP.0b013e318231cf03.[Link]

28. Francoeur RT, Noonan RJ. The Continuum complete International Encyclopedia of Sexuality: Updated with more countries [Internet]. 2006 [cited 2016 August 3]. [Full Text]

29. Najafi-sharjabad F, Zainiyah S, Yahya S, Rahman HA, Hanafiah M. Barriers of Modern Contraceptive Practices among Asian Women : A Mini Literature Review. Global J Health Sci. 2013;5(5):181-92. doi:10.5539/gjhs.v5n5p181.[Full Text]

30. Oyedokun Amos O. Determinants of contraceptive usage: Lesson from Women in Osun State, Nigeria. Journal of Humanities and Social Science. 2007;1(2):1-14. 
31. The ACQUIRE Project. Mobilizing married youth in Nepal to improve reproductive health: The Reproductive Health for Married Adolescent Couples Project, Nepal, 2005-2007. E\&R Report No. 12. New York: EngenderHealth/The ACQUIRE Project; 2008 August. 60p.[Full Text]

32. Daniel EE, Masilamani R, Rahman M. The Effect of Community-Based Reproductive Health Communication Interventions on Contraceptive Use Among Young Married Couples in Bihar, India. Int Fam Plan Perspect. 2008;34(4):189-97.[Full Text]

33. Aguilar AM, Cortez R. Family Planning: The Hidden Need of Married adolescents in Nepal. World Bank; 2015 January: $1-4$.[Full Text]

34. Ahmad GS, Singh R, Agrawal S, Raja S, Ali H. A Study of Adolescent Problems and their Knowledge, Attitude and Practice regarding Health and Rights in the Eastern Region of Nepal. International Journal of Recent Scientific Research 2015 May 28;6(5):4312-4319.[Full Text]

35. UNFPA, CREPHA, UNICEF, Ministry of Health and Population Department of Health Services Family Health Division. The Qualitative Study on Assessing Supply Side Constraints Affecting the Quality of Adolescent Friendly Health Services and the Barriers for Service Utilization in Nepal [Internet]; 2015 January. 119p.[Full Text]

36. The World Bank Group. HIV/AIDS in Nepal [Internet]. World Bank Group; 2012 July 10 [updated 2016; cited 2016 August 2]. [Link]

37. Gubhaju BB. Adolescent Reproductive Health in Asia. Paper presented at: "South East Asia's Population in a Changing Asian Context”; 2002 June 10-13; Bangkok, Thailand. [Full Text]

38. Pradhan A, Strachan M. Adolescent Reproductive Health in Nepal, Status, Policies, Programmes, and Issues. UNAIDS, Future Group International; 2003 Jan. 27p.[Full Text]

39. Regmi PR, Simkhada P, Teijlingen ER Van. "There are too many naked pictures found in papers and on the net": Factors encouraging premarital sex among young people of Nepal. Health Science Journal 2010;4 (3):169-81.[Full Text]

40. Mathur S, Malhotra A, Mehta M. Adolescent girls' Life aspirations and reproductive health in Nepal. Reproductive Health Matter 2001 May; 9(17): 91-100.[Link]

41. Stone N, Ingham R, Simkhada P. Knowledge of Sexual Health Issues among Unmarried Young People in Nepal. Asia-Pacific Population Journal 2003 June;18(2):32-39. [Link]
42. UNFPA Nepal. Fact Sheet: Comprehensive Sexuality Education in Nepal. 2016 December. [Full Text]

43. Marston C, King E. Factors that shape young people's sexual behaviour a systematic review. Lancet 2006; 368 : 1581-86.[Link]

44. Tamang BA, Puri M, Shrestha D. Sexual Behaviour and Risk Perceptions among Young Men in Border Towns of Nepal. Asia-Pacific Population Journal 2001 June;16(2):195210.[FullText]

45. Brown A, Jejeebhoy SJ, Shah I, Yount KM. Sexual relations among young people in developing countries : evidence from WHO case studies. Geneva Switzerland: Department of Reproductive Health and Research Family and Community Health World Health Organization; 2001. 63p.[FullText]

46. Simkhada P, Van Teijlingen ER, Regmi PR. "Boys Remain Prestigious, Girls Become Prostitutes": Socio-Cultural Context of Relationships and Sex among Young People in Nepal. Global J Health Sci. 2010;2(1):60-72.[Full Text]

47. Ministry of Health Department of Health Services. Annual Report 2014/2015. Kathmandu Nepal, Department of Health Services; 2016. 520p.[Full Text]

48. Government of Nepal Ministry of Health and Population. Nepal Health Sector Programme - Implementation Plan II (NHSP -IP2) 2010 - 2015. Kathmandu Nepal: Ministry of Health and Population;2010 April 7. 142p.[Full Text]

49. Baral SC, Khatri R, Schildbach E, Schmitz K, Silwal PR, Van Teijlingen E. National Adolescent Sexual and Reproductive Health Programme Mid-Term Evaluation Report. GIZ, Department of Health Services; 2013 August. 40p. [Full Text]

50. Family Planning Association of Nepal (FPAN). What we do [Internet]. Kathmandu Nepal: FPAN; 2015 [cited 2016 July 31]. [Link]

51. Marie Stopes International Nepal. Centres [Internet]. 2016 [cited 2016 August 13]. [Link]

52. Marie Stopes International Nepal. Youths [Internet]. 2016 [cited 2016 August 13]. [Link] 